\title{
HARD MACHINABLE MACHINING OF COBALT SUPER ALLOYS
}

\author{
Robert ČEP ${ }^{1}$, Adam JANÁSEK ${ }^{1}$, Jana PETRƯ $^{1}$, Lenka ČEPOVÁ ${ }^{1}$, \\ Marek SADÍLEK ${ }^{1}$, Jiří KRATOCHVÍL ${ }^{1}$
}

${ }^{1} 346$ - Department of Machining and Assembly, Faculty of Mechanical Engineering, VŠB Technical University of Ostrava, 17. listopadu 15/2172, 70833 Ostrava - Poruba, Czech Republic, robert.cep@vsb.cz, adam.janasek@vsb.cz,jana.petru@vsb.cz, lenka.cepova@vsb.cz. marek.sadilek@vsb.cz, jiri.kratochvil@vsb.cz

Keywords: Difficult-to-cut Material; Super Alloys; Thermal Loading; Machining.

\begin{abstract}
The article deals with difficult-to-machine cobalt super alloys. The main aim is to test the basic properties of cobalt super alloys and propose suitable cutting materials and machining parameters under the designation 188 when machining. Although the development of technology in chipless machining such as moulding, precision casting and other manufacturing methods continues to advance, machining is still the leading choice for piece production, typical for energy and chemical engineering. Nowadays, super alloys are commonly used in turbine engines in regions that are subject to high temperatures, which require high strength, high temperature resistance, phase stability, as well as corrosion or oxidation resistance.
\end{abstract}

\section{INTRODUCTION}

Many types of steel, alloys and cast irons can be difficult-to-machine. In terms of machining, it can be noted that for all of these materials, common technological conditions and evaluation of current, new, and developing material properties can be specified. Some characteristic properties of machined materials, such as material structure and physicochemical properties, allow for the most convenient cutting material and tools to be chosen.

The cutting tools machining efficiency depends on the correct choice of the following inseperable factors: machining material, machine tool power, maximum speed, machine tool and fixture status [7]. Effective machining requires the equipment with suitable cutting tools and the determination of a suitable feed rate. The alloys are mechanically reinforcement by the process of cold forming making it necessary to avoid interruption of the cut [1]. The availability of super alloys throughout the past decades has led to a continuous increase in turbine entry temperatures and this trend is expected to continue. Future direction in alloy development focuses on the reduction of weight, improvement in oxidation and corrosion resistance while maintaining the strength of the alloy. Another focus of the alloy is to reduce the cost of super alloys.

\section{THERMAL LOADING OF THE CUTTING EDGE WHEN MACHINING SUPER ALLOYS}

The thermal stress of the cutting edge is affected by the ability to absorb heat, created in the cutting area, expressed by the thermal characteristics of heat capacity, coefficient of heat conduction and density. The material is sensitive to thermal interaction between tool and the chip at low values of thermal conduction. If the most difficult-to-machine materials have a thermal 
conductivity, heat generated at the cutting edges, the temperature is concentrated at the cutting area and causes the large heat accumulation in the tool. Maximum temperatures of difficult-tomachine materials occur very close to the cutting edge, even though the length of the tool's contact and material correspond to the length of contact for steel. [2]

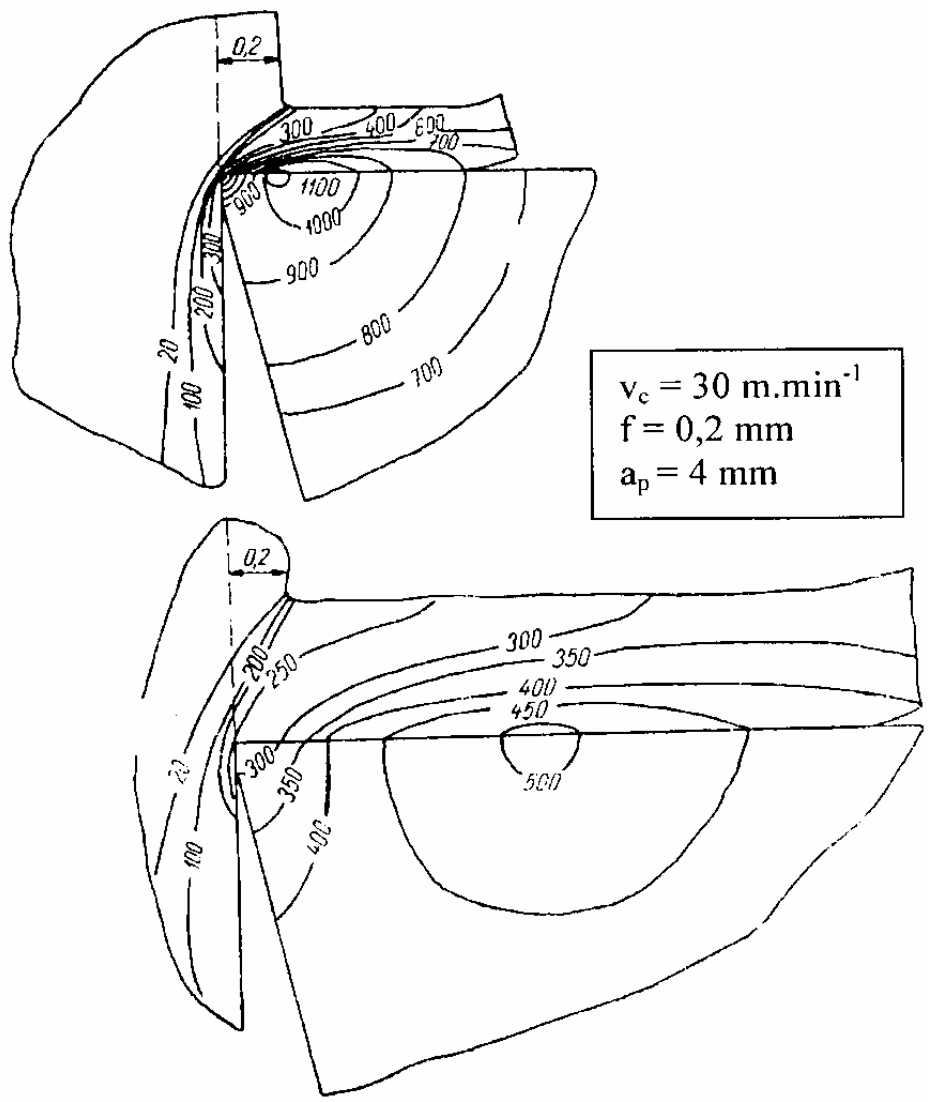

Figure 1: Investigation of the distribution of temperature field when machining, above - difficultto-cut material, below - Carbon steel. [3]

The temperature in the cutting zone is influenced by the cutting conditions, tool geometry, tool material and cutting fluid. The cutting fluid is one of the most important factors which effects the productivity of difficult-to-machine materials [4]. The temperature reduction in the cutting edge, thanks to the applications of cutting fluids, aims at increasing the tool life.

\section{INTRODUCTION TO MEASUREMENTS}

The material tested is made of a super alloy, and cobalt-base, under the industry name: No. 188 with the chemical composition $22 \% \mathrm{Cr} ; 22 \% \mathrm{Ni} ; 14 \% \mathrm{~W} ; 0.08 \% \mathrm{La} ; 41.92 \% \mathrm{Co}$, and is used in aircraft engines. The aim was to test the properties of this difficult to machine material and suggest suitable cutting materials and cutting parameters. 
The temperature at the cutting edge was measured using an MAURER AE 1012 device. The device measures the temperature by means of infrared radiation. The device is calibrated by the black radiator $[5,6]$. In certain areas with bright surfaces measurement error is possible, due to decreasing heat radiation, which can be corrected using a known temperature [6].

TURN cutting conditions:

Diameter of material:

$\mathrm{d}=12 \mathrm{~mm}$

Depth of cut:

$\mathrm{a}_{\mathrm{p}}=1 \mathrm{~mm}$

Feed rate:

$\mathrm{f}=0.05 \mathrm{~mm}$

a) Turning - cutting material S20 (ISO P15-P20)

Table 1: Temperature measurement when using the S20 tool.

\begin{tabular}{|c|c|}
\hline $\begin{array}{c}\text { Cutting speed } \\
\mathrm{v}_{\mathrm{c}}[\mathrm{m} / \mathrm{min}]\end{array}$ & $\begin{array}{c}\text { Temperature in the cutting area } \\
\mathrm{T}\left[{ }^{\circ} \mathrm{C}\right]\end{array}$ \\
\hline 63 & below 500 \\
\hline 250 & $550-600$ \\
\hline 400 & $700-730$ \\
\hline 500 & $800-820$ \\
\hline 800 & $920-950$ \\
\hline
\end{tabular}

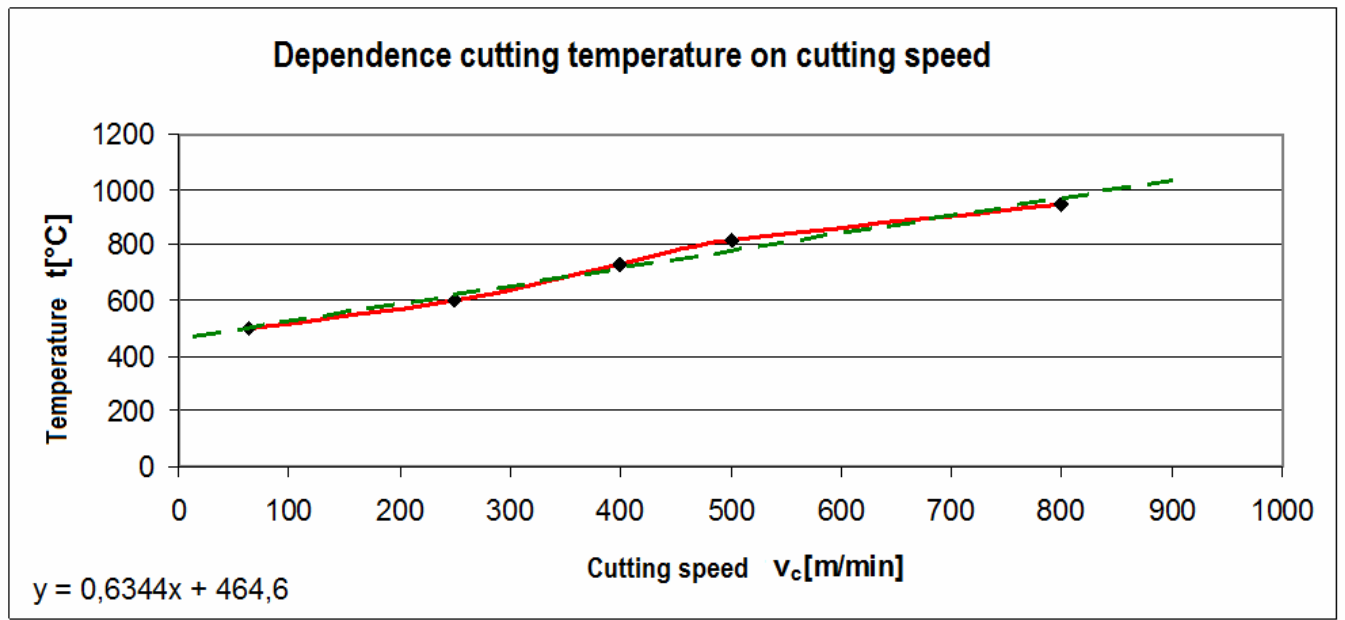

Figure 2: Dependence of temperature on the cutting speed of S20 (ISO P15-P20).

Tab. 1 and Fig. 2 show that the temperature grows almost linearly with higher cutting speeds. The cutting tool is significantly heated and deformed at high speeds.

b) Turning - cutting material IS0 K20-K30 
SCIENTIFIC PROCEEDINGS 2012, Faculty of Mechanical Engineering, STU in Bratislava Vol. 20, 2012, pp. 42-47, DOI: 10.2478/v10228-012-0007-6

Table 2: Temperature measurements when using the ISO K20-K30 tool.

\begin{tabular}{|c|c|}
\hline $\begin{array}{c}\text { Cutting speed } \\
\mathrm{v}_{\mathrm{c}}[\mathrm{m} / \mathrm{min}]\end{array}$ & $\begin{array}{c}\text { Temperature in the cutting area } \\
\mathrm{T}\left[{ }^{\circ} \mathrm{C}\right]\end{array}$ \\
\hline \hline 63 & $560-570$ \\
\hline 100 & $570-580$ \\
\hline 250 & $580-590$ \\
\hline 400 & $620-630$ \\
\hline 500 & $680-690$ \\
\hline 800 & $750-770$ \\
\hline
\end{tabular}

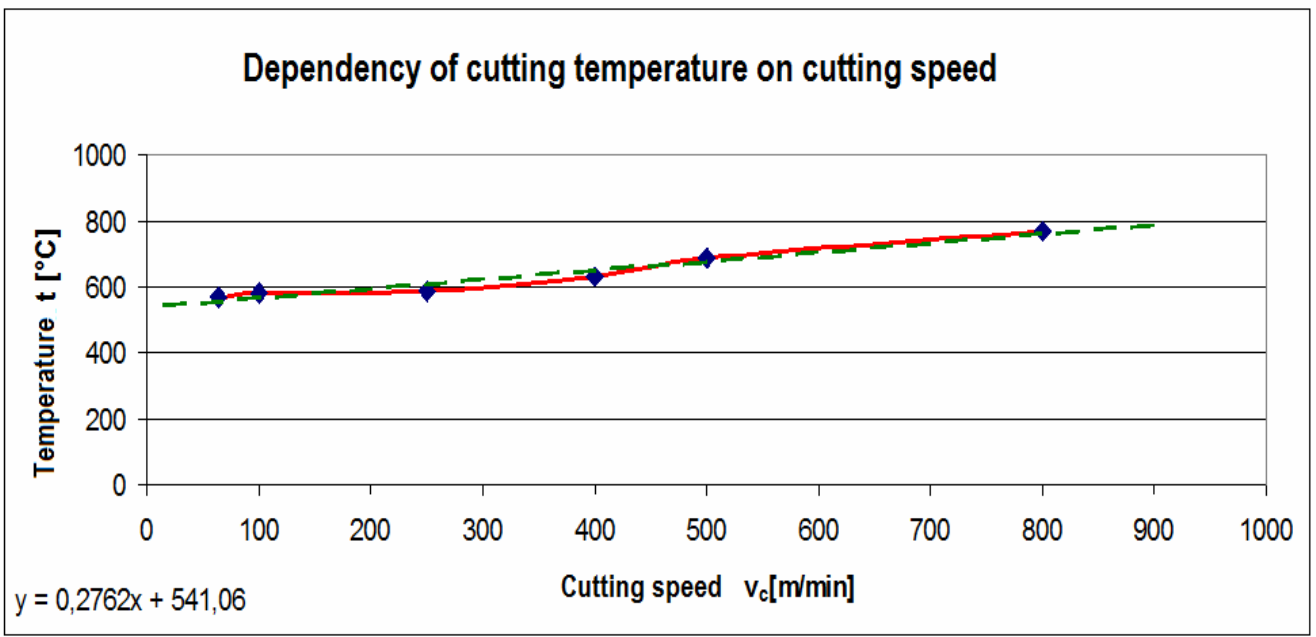

Figure 3: Dependence of temperature on the cutting speed of ISO K20-K30.

The temperature at higher speeds, when using the coated ISO K20-K30 tool compared with the S20 cutting tool, is reduced by approximately $100-150^{\circ} \mathrm{C}$. The temperature is nearly the same at "optimal" cutting speed $200 \mathrm{~m} \cdot \mathrm{min}^{-1}$. The temperature characteristic also increases almost linearly as with the previous tool.

c) Turning - cutting material D240

Table 3: Temperature measured when using the D240 tool.

\begin{tabular}{|c|c|}
\hline $\begin{array}{c}\text { Cutting speed } \\
\mathrm{v}_{\mathrm{c}}[\mathrm{m} / \mathrm{min}]\end{array}$ & $\begin{array}{c}\text { Temperature in the cutting area } \\
\mathrm{T}\left[{ }^{\circ} \mathrm{C}\right]\end{array}$ \\
\hline \hline 63 & - \\
\hline 100 & - \\
\hline 160 & - \\
\hline 250 & $500-600$ \\
\hline
\end{tabular}




\begin{tabular}{|c|c|}
400 & $750-800$ \\
\hline 500 & $900-940$ \\
\hline 800 & $1000-1100$ \\
\hline
\end{tabular}

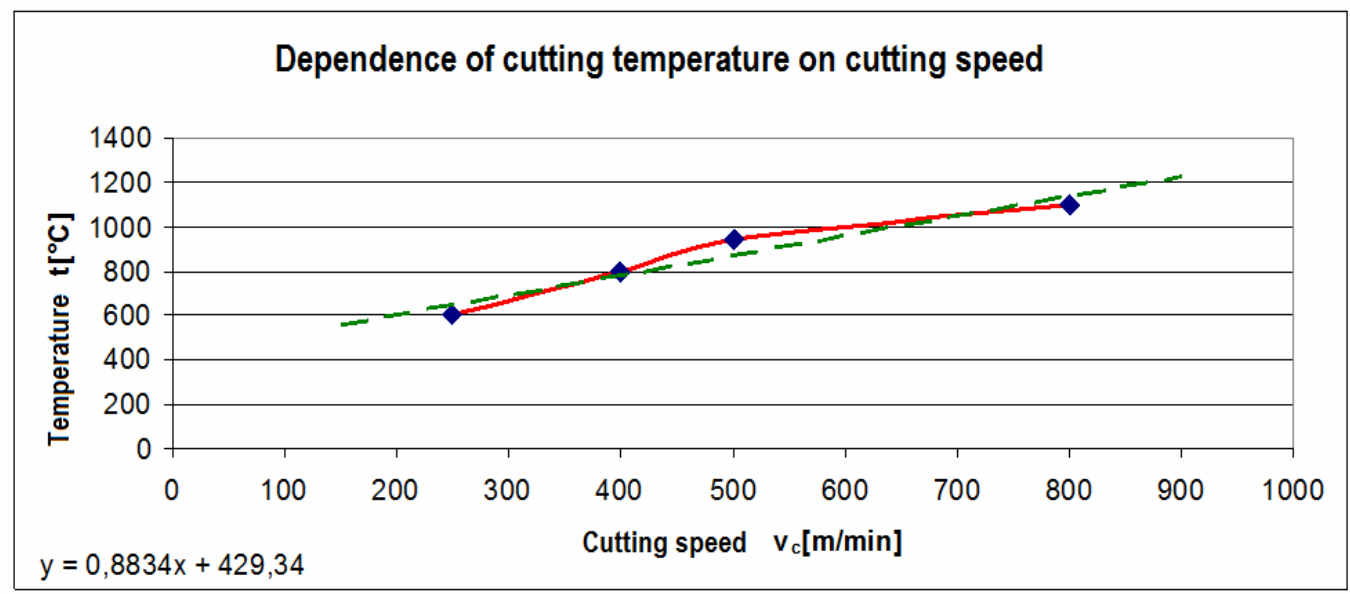

Figure 4: Dependence of temperature on the cutting speed of D240.

Using a ceramic cutting insert, namely D240, it was necessary to start the measurement at higher cutting speeds because the measuring device (MAURER AE 1012) begins to measure at temperatures of approximately $550^{\circ} \mathrm{C}$. The temperature was very high in comparison with the cemented carbide and this is a result of the inappropriate tool for this type of machined material, which is very tough.

\section{EVALUATION OF EXPERIMENT AND CONCLUSIONS}

The following three cutting tools were used in the experiment, non-coated cemented carbide S20 (ISO P15 - P20), coated cemented carbide ISO K20-K30 and ceramic D240. The device for temperature measuring MAURER AE 1012 begins to measure at temperatures of approximately $550^{\circ} \mathrm{C}$, requiring higher cutting speeds than are appropriate for these types of tools in machining super alloys. Overall, cutting with a ceramic tool created very high temperatures, making this cutting tool inappropriate. The reasons for this are a higher toughness not suitable for this type of material. If we use the cemented carbide, both coated and non-coated, the temperature will decrease in the cutting area. Non-coated cemented carbide showed a slightly higher temperature at different cutting speeds.

The experiment shows that it is more cost effective to use non-coated cemented carbide with a high content of cobalt. If a higher tool-life is desired, it is necessary to choose the maximal cutting speed to be between $20-30 \mathrm{~m} \cdot \mathrm{min}^{-1}$, with a depth of cut no more than $1 \mathrm{~mm}$ and feed rate of approximately $1 \mathrm{~mm}$. It is also required to keep a high rigidity and appropriate tool geometry with a chip former. 


\section{REFERENCES}

[1] CEP, Robert; NESLUSAN, Miroslav; BARISIC, Branimir. (2008). Chip Formation Analysis During Hard Turning. Strojarstvo, vol 50, No. 6, pp. 337 - 345. ISSN 0562 1887, Zagreb.

[2] VASILKO, Karol. Machining of tatianium and its alloys. Engineering yearbook, 1985, p. 139-146.

[3] NESLUŠAN, Miroslav; CZÁN, Andrej. Machining of difficult-to-machine materials. 1. publication. Žilina: University of Žilina, 2002. p. 127.

[4] ČEP, Robert. Incerasing of manufacturing precision by powerful cutting tools. In WORKSHOP for Faculty of Mechanical Engineering 2002. Ostrava : VŠB-TU Ostrava, 2002, p. 13-16. ISBN 80-248-0051-9.

[5] BILÍK, Oldřich; Kubiš, Miroslav. Theory manual into practice machining. 1. publication. Ostrava: Publishing centre: VŠB, 1991.

[6] BRUNA, Jiří. Machining of hard machinable cobalt superalloys. Ostrava, 2005. Bachalor thesis. VŠB - Technical University of Ostrava. Head of bachalor thesis: Robert ČEP.

[7] Ling Feng: Metallurgical Machinery. ANHUI LINGFENG METALLURGICAL MACHINERY CO., LTD. [online]. 2011. published [cited 2012-10-10]. Available from: http:/www.lingfengchina.com/en/display.asp?id=12 